\title{
CADEIA DE SUPRIMENTOS VERDE E AS ACÕES DO PACTO DA PECUÁRIA DO PROGRAMA “CONEXÕES SUSTENTÁVEIS” SÃO PAULO - AMAZÔNIA
}

Geraldino Carneiro de Araújo"

Maria Tereza Saraiva de Souza**

Adriana dos Santos Pimenta***

RESUMO: O objetivo deste trabalho é analisar a sustentabilidade ao longo da cadeia de suprimentos da bovinocultura de corte considerando as ações do pacto da pecuária do programa "Conexões Sustentáveis" São Paulo - Amazônia, segundo a teoria da cadeia de suprimentos verde. Teoricamente foram tratados os temas cadeia de suprimentos da bovinocultura de corte e cadeia de suprimentos verde. Tratase de uma pesquisa exploratória e descritiva, com um estudo de caso qualitativo; utilizaram-se como fontes de evidência documentos, registros em arquivo e entrevista. Os resultados apontam o contexto da pecuária na Amazônia, a descrição do programa e relaciona os dados do pacto da pecuária com a teoria de cadeia de suprimentos verde. Conclui-se que o programa, apesar de apresentar problemas para sua efetivação, é uma iniciativa que busca o desenvolvimento de cadeia de suprimentos verde da bovinocultura de corte.

PALAVRAS-CHAVE: Cadeia de Suprimentos Verde; Frigoríficos; Pecuaristas.

\section{GREEN SUPPLEMENTS CHAIN AND THE ACTIVITIES OF THE LIVESTOCK CONTRACT OF THE SUSTAINABLE CONNECTIONS PROGRAM SÃO PAULO - AMAZON}

ABSTRACT: Sustainability throughout the supplement chain of meat livestock is analyzed while taking into account the activities of the livestock pact of the São PauloAmazon Sustainable Connections program, according to the green supplement chain theory. The themes meat livestock supplements chain and the green supplements chain are discussed. Current exploratory and descriptive research deal with a

\footnotetext{
* Administrador; Mestre em Agronegócios; Doutorando em Administração e Docente na Universidade Federal de Mato Grosso do Sul - UFMS/CPAR; Campus Paranaíba, (MS), Brasil; E-mail: geraldino.araujo@gmail.com

** Doutora e Mestre em Administração de Empresas pela Escola de Administração de Empresas de São Paulo da Fundação Getúlio Vargas - EAESP/FGV, São Paulo, (SP), Brasil.

*** Graduanda em Administração pela Universidade Nove de Julho - UNINOVE, São Paulo, (SP), Brasil.
} 
qualitative case with documents, registers and interviews as sources. Results reveal the livestock context in the Amazon, describes the program and relates data of the livestock pact with the theory of green supplements chain. Results show that the program, albeit full of problems for its materialization, is an initiative that focuses on the development of the green supplement chain of meat livestock.

KEY WORDS: Green Supplements Chain; Abattoirs; Cattle Breeders.

\section{INTRODUÇÃO}

A cadeia de suprimentos da bovinocultura de corte vem sendo apontada como uma das principais responsáveis pelo desmatamento da Amazônia (SMERALDI; MAY, 2008). A Amazônia é um bioma muito importante, entretanto produtores rurais, incentivados pelas indústrias, têm desmatado a floresta para aumentarem sua produção (GREENPEACE, 2009). Envolvidos neste fluxo produtivo estão os pecuaristas que fornecem gado para frigoríficos espalhados pelo país que, por sua vez, são fornecedores de carne para varejos em vários municípios brasileiros (ONG REPÓRTER BRASIL E PAPEL SOCIAL COMUNICAÇÃO, 2008).

O programa "Conexões Sustentáveis" tem como intuito principal preservar a Amazônia, objetivando a mobilização das cadeias de valor de setores específicos para a preservação da floresta amazônica e seus povos (CONEXÕES SUSTENTÁVEIS, 2012a). As empresas signatárias dos pactos setoriais do programa assumem o compromisso de adquirirem produtos que estejam dentro das regras estabelecidas. Todos os agentes são corresponsáveis pelas ações dos demais (CONEXÕES SUSTENTÁVEIS, 2012b; 2012f).

Essa pesquisa parte do pressuposto que o programa "Conexões Sustentáveis" envolve os princípios de cadeia de suprimentos verde (BEAMON, 1999a; RAO; HOLT, 2005; SRIVASTAVA, 2007; DARNALL et al., 2008; WALKER et al., 2008), sendo o foco do estudo o pacto da pecuária. Entende-se que são muitos os impactos negativos que a bovinocultura de corte causa ao meio ambiente. Neste sentido, o objetivo deste artigo é analisar a sustentabilidade ao longo da cadeia de suprimentos da bovinocultura de corte considerando as ações do pacto da pecuária do programa 
"Conexões Sustentáveis" São Paulo - Amazônia, segundo a teoria da cadeia de suprimentos verde.

Para o desenvolvimento deste estudo optou-se por uma abordagem qualitativa a partir de um estudo de caso, o programa "Conexões Sustentáveis" São Paulo - Amazônia. Na coleta de dados foram utilizadas três fontes de evidência: a documentação, os registros em arquivos e a entrevista. Os dados foram tratados conforme a teoria de análise de conteúdo.

\section{FUNDAMENTAÇÃO TEÓRICA}

Teoricamente são tradados os temas: cadeia de suprimentos da bovinocultura de corte e cadeia de suprimentos verde.

\subsection{CADEIA DE SUPRIMENTOS DA BOVINOCULTURA DE CORTE}

A cadeia de suprimentos é o conjunto de empresas que fornecem e compram materiais, ou seja, são empresas que se envolvem na fabricação de um produto para colocá-lo à disposição do usuário final; trata-se de um alinhamento das empresas para fornecer produtos ou serviços ao mercado por meio de ligações a montante e a jusante (BECHTEL; JAYARAM, 1997; MENTZER et al., 2001). A cadeia de suprimentos refere-se às relações entre as empresas, por meio de seus processos, para criar um sistema de valor; busca-se maximizar os potenciais esforços, diminuir os desperdícios, aumentar a eficiência e a eficácia dos processos de negócios, visando aumentar a competitividade da cadeia de suprimentos (CHRISTOPHER, 1992; LAZZARINI et al., 2001).

Beamon (1999b) e Pigatto e Alcântara (2006) conceituam cadeia de suprimentos, no contexto do agronegócio, como um conjunto de processos integrados, que envolve desde os fornecedores da indústria (produtor rural ou mesmo outra indústria), fornecedores de insumos, indústria de apoio, distribuidores e outros agentes, que se organizam para que as matérias-primas sejam manufaturadas em produtos finais e cheguem aos consumidores. 
Segundo o United States Departament of Agriculture (USDA, 2011) o Brasil é um dos grandes produtores mundiais e o maior exportador de carne vermelha. O Ministério da Agricultura, Pecuária e Abastecimento (MAPA, 2011) afirma que o Brasil faz negócios com aproximadamente 130 nações; para abastecer o globo nos últimos 10 anos o número de cabeças de gado no país teve um incremento de cerca de $20 \%$.

A cadeia de suprimentos da bovinocultura de corte brasileira é uma das mais complexas em relação à estruturação e aos agentes envolvidos, exercendo um papel fundamental ao longo da história e do desenvolvimento brasileiros. A sequência produtiva, no caso da carne bovina, envolve: produção de insumos, produtores de bovinos, abatedouros/frigoríficos (agroindústria) e rede de distribuição (atacado e varejo) (MICHELS; SPROESSER; MENDONÇA, 2001). A cadeia de suprimentos da bovinocultura de corte é apresentada no Quadro 1:

Quadro 1. Cadeia de suprimentos da bovinocultura de corte

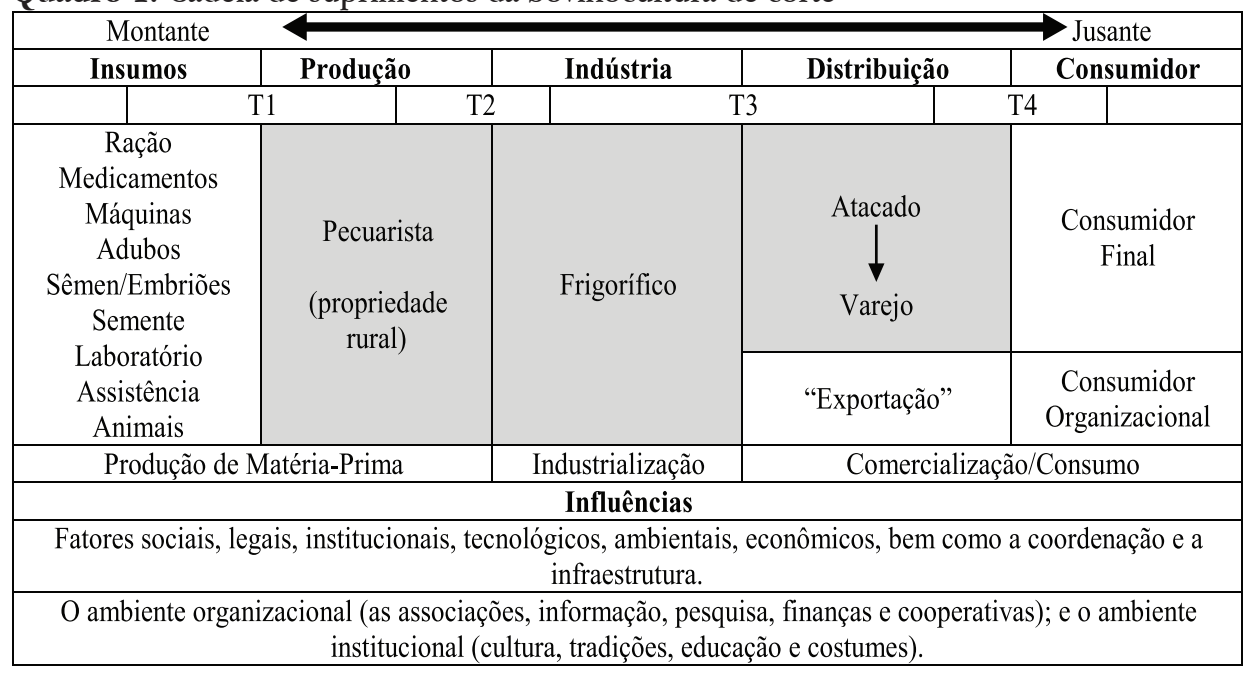

Fonte: Adaptado de Araújo (2006, p. 57).

O Quadro 1 evidencia o fluxo produtivo da carne bovina considerando as transações dos agentes econômicos da cadeia de suprimentos; as transações são representadas pela letra T (por exemplo, a transação três - T3 - é aquela que ocorre 
entre o produtor e a indústria). A sequência produtiva mostra a interdependência entre os agentes econômicos para produção e distribuição de carne bovina. Há destaque para a agroindústria, neste caso específico, o frigorífico de abate e processamento de bovinos, pois é considerado o agente coordenador. Apesar da pouca estruturação, tem a finalidade de aprimorar a gestão na cadeia e garantir a qualidade do produto por meio do processo de transação de informações, o que contribui para a satisfação dos clientes e para a redução dos custos e das perdas em todas as etapas da cadeia (LAMBERT; COOPER, 2000; BORRÁS; TOLEDO, 2006).

A produção de bovinos no Brasil está atrelada a uma série de graves problemas sociais e ambientais (SEVERO; MIGUEL, 2006; DIAS-FILHO, 2007; ONG REPÓRTER BRASIL E PAPEL SOCIAL COMUNICAÇÃO, 2008; GREENPEACE, 2009). Além de dificuldades decorrentes da febre aftosa, baixa coordenação entre os agentes e a informalidade com abates clandestinos (BÁNKUTI; SOUZA FILHO, 2006). Entretanto, a produção de carne bovina tem um grande público consumidor: a produção nacional abastece tanto o mercado interno quanto externo (MICHELS; SPROESSER; MENDONÇA, 2001); se trata, portanto, de uma atividade perene. A atividade pecuária cresceu diferentemente em várias regióes do Brasil, assim, a cadeia de suprimentos da bovinocultura de corte expandiu-se de forma desorganizada, resultando em desmatamentos e conflitos de ordem fundiária (SMERALDI; MAY, 2008).

\subsection{CADEIA DE SUPRIMENTOS VERDE}

Para Sarkis (2003) as práticas de negócios sustentáveis estão recebendo uma maior atenção de pesquisadores e profissionais. Historicamente, Beamon (1999a), verificando os aspectos ambientais de uma cadeia de suprimentos, tais como a pressão da sociedade, controle dos resíduos sólidos, uso racional dos recursos naturais, controle de poluição e legislação, propôs um modelo de gestão que atendesse atributos ambientais - seria o início das discussões sobre a cadeia de suprimentos verde. A gestão da cadeia de suprimentos verde é como uma inovação que auxilia o desenvolvimento de estratégias organizacionais do tipo "ganha-ganha" (ZHU; SARKIS; LAI, 2007). 
Um grande número de definições possíveis de gestão de suprimentos verde tem sido formulado (ZHU; SARKIS, 2004): a) Cadeia verde, que se refere ao modo pelo qual as inovações na gestão da cadeia de suprimentos consideram o meio ambiente; b) Gestão ambiental da cadeia de suprimentos, em que há o envolvimento da função de compras em atividades que incluem a redução, reciclagem, reutilização e substituição de materiais; c) Acompanhamento e melhoria do desempenho ambiental na cadeia de suprimentos; d) Rede de fornecedores, distribuidores e consumidores, que também inclui transporte entre o fornecedor e o consumidor, bem como ao consumidor final. Essas definições mostram que as pesquisas sobre cadeia de suprimentos verde são variadas e consideram aspectos diferentes. A definição da finalidade das cadeias de suprimentos verdes tem variado de monitoramento reativo de programas ambientais para práticas de gestão mais proativas, se possível com a incorporação de inovações.

A falta de consenso da prática e da definição de cadeia de suprimentos verde não é surpreendente, uma vez que se situa na confluência de dois elementos empresariais: a gestão ambiental e a gestão da cadeia de suprimentos, que são áreas de estudo relativamente novas (ZHU; SARKIS, 2004). Diante desta constatação são apresentadas algumas pesquisas realizadas. Srivastava (2007) apresenta uma visão abrangente e integrada da literatura publicada sobre todos os aspectos e facetas da gestão da cadeia de suprimentos verde; os estudos foram classificados em três grandes grupos: 1) No início a literatura centrou-se na necessidade de ressaltar a importância da gestão da cadeia de suprimentos verde; 2) Após esta fase os estudos passaram a considerar o design verde enfatizando o design ambientalmente consciente (ECD) e a avaliação/análise ciclo de vida (LCA) do produto; 3) E, por fim, a área de operações verdes, que foi subdividida em gestão de resíduos, manufatura e remanufatura e logística reversa.

Semelhante ao conceito de gestão da cadeia de suprimentos, o limite dos estudos que tratam da cadeia de suprimentos verde depende do objetivo do pesquisador. A pesquisa em cadeia de suprimentos verde abrange uma variedade de questões que vão desde a pesquisa organizacional e prática, até modelos prescritivos para avaliação da gestão da cadeia de suprimentos verde. Uma vez que a literatura nesta área está em expansão, os autores concentraram-se em cinco práticas da 
gestão da cadeia de suprimentos verde: gestão ambiental interna, compras verdes, cooperação com clientes. As compras verdes parecem ter grande atenção dentro das empresas líderes em países desenvolvidos (ZHU; SARKIS, 2006).

A cadeia de suprimentos pode se organizar de forma mais sustentável, incorporando ações intra e interorganizacionais envolvendo aspectos ambientais; uma vez alcançado este patamar, pode ser considerada como uma cadeia de suprimentos verde (RAO; HOLT, 2005). Assim, a gestão da cadeia de suprimentos verde representa um conjunto recente e importante de práticas de gestão ambiental inter e intraorganizacional, é projetada para incorporar considerações ambientais nas decisões em cada etapa da gestão (ZHU et al., 2008).

A implementação da gestão da cadeia de suprimentos verde reduz ou elimina impactos ambientais decorrentes de atividades produtivas nos processos de compra, produção, distribuição, prestação de serviços, e também no processo de logística reversa e na gestão de resíduos. Isto ocorre particularmente se houver o envolvimento dos fornecedores, distribuidores, empresas parceiras, concorrentes, governo e consumidores, ou seja, dos principais membros da cadeia de suprimentos (RAO; HOLT, 2005). Um dos aspectos fundamentais para cadeias de suprimentos verdes é melhorar o desempenho econômico e ambiental ao longo dos relacionamentos cliente-fornecedor, isto pode não só gerar benefícios ambientais, mas também benefícios para o negócio (ZHU; SARKIS, 2006).

As empresas que se envolvem com os conceitos da cadeia de suprimentos verde avaliam o desempenho ambiental dos fornecedores e tomam medidas que garantam a qualidade ambiental de produtos e serviços (DARNALL; JOLLEY; HANDFIELD, 2008). A gestão da cadeia de suprimentos verde pode envolver iniciativas ambientais nas funções de compra; no processo produtivo ou na cadeia de suprimentos interna; nas funções de distribuição de produtos e serviços; e na logística reversa, que inclui o envolvimento dos membros da cadeia de suprimentos para reduzirem ou eliminarem os impactos ambientais (RAO; HOLT, 2005). A gestão da cadeia de suprimento verde envolve a seleção de fornecedores com base em seu desempenho ambiental, assim clientes fazem negócios apenas com aqueles que atendem certas normas ambientais ou padrões.

Para Zsidisin e Siferd (2001) as estratégias de compra verde têm uma 
participação relevante na gestão da sustentabilidade ambiental na cadeia de suprimentos. As compras verdes incluem uma grande variedade de atividades, que incluem desde a cooperação entre as organizações para minimização de impactos ambientais até as questões logísticas para o retorno dos produtos no seu final de vida útil. Há ainda uma atividade que consiste na aquisição impulsionada internamente por atividades ambientais, tais como reciclagem, reutilização e redução de materiais de fontes não renováveis (MIN; GALLE, 2001).

A compra verde incide sobre a entrada de materiais ou no segmento a montante de um produto na organização da cadeia de suprimentos. Alguns fatores-chave para as compras verdes incluem especificações para os fornecedores, que tratam de: requisitos ambientais para os itens comprados; cooperação com fornecedores para objetivos ambientais; auditorias ambientais para a gestão interna do fornecedor; e certificação dos fornecedores ISO14001 (ZHU; SARKIS; LAI, 2008).

\section{MÉTODO}

Este estudo se desenvolveu considerando dois tipos de pesquisa: a exploratória e a descritiva. Para Hair Jr. et al. (2005), na pesquisa exploratória desenvolve-se um completo referencial teórico, e este pode vir a ser a etapa inicial de um plano descritivo. Para Cooper e Schindler (2003) a pesquisa descritiva procura descrever um fenômeno ou suas características associadas. $\mathrm{O}$ método de pesquisa que foi desenvolvido no trabalho foi o qualitativo (COLLIS; HUSSEY, 2005). A abordagem qualitativa se justifica por ser uma maneira de entender a natureza de um determinado fenômeno social, e também há de se considerar que determinadas questões de pesquisa exigem uma conotação qualitativa (RICHARDSON, 2008).

$\mathrm{O}$ método de estudo de caso visa investigar fenômenos contemporâneos e reais, priorizando a compreensão de fatos. Sobre a utilização de dois tipos de pesquisa, exploratória e descritiva, ressalta-se que na estratégia de pesquisa estudo de caso qualitativo a ferramenta exploratória pode ser combinada com a descritiva para expor ou testar hipóteses (YIN, 2010). Escolheu-se um caso único para ser analisado em profundidade: o programa "Conexões Sustentáveis" São Paulo - Amazônia. 
Escolheu-se este programa por ser inovador, por envolver o maior município e o maior bioma brasileiro. Para a coleta de dados, Yin (2010) ressalta as seis fontes de evidência (documentação, registro em arquivo, entrevistas, observações diretas, observação participante e artefatos físicos); neste estudo utilizaram-se três destas:

1) Documentação: este tipo de informação pode tomar uma variedade de formas, tais como minutas de reuniões, relatórios escritos de eventos, documentos administrativos, registros internos, estudos formais ou avaliações, recortes de notícias e outros artigos que apareçam na mídia; salienta-se que esses e outros tipos de documentos estão sendo, cada vez mais, disponibilizados pela Internet (YIN, 2010). Godoy (1995) considera que a análise de documentos é uma valiosa técnica de abordagem de dados qualitativos favorecendo a compreensão do problema investigado. A análise documental configura-se como um procedimento que fornece informações sobre determinado fenômeno de forma contextualizada (MAY, 2004). Na bome page do programa "Conexões Sustentáveis" foram encontrados registros sobre o acompanhamento do pacto da pecuária; este estudo selecionou os seguintes: Informações gerais sobre o programa "Conexões Sustentáveis", os pactos setoriais e o acompanhamento dos pactos (CONEXÕES SUSTENTÁVEIS, 2012a; 2012d; 2012e); Dados específicos sobre o pacto da pecuária (CONEXÕES SUSTENTÁVEIS, 2012b; 2012c; 2012f); Os resultados do acompanhamento do programa (CONEXÕES SUSTENTÁVEIS, 2012g; 2012h; 2012i); E o posicionamento das empresas signatárias (CONEXÕES SUSTENTÁVEIS, 2012j; 2012k).

2) Registros em arquivos: são arquivos de uso público, registros de serviços, registros organizacionais, orçamentos, registros pessoais, dados de levantamento e até mesmo mapas e gráficos; estes registros podem ser importantes e se tornam objeto de recuperação extensa (YIN, 2010). Foram estudados os seguintes documentos: um estudo realizado pela ONG Repórter Brasil e Papel Social Comunicação (2008), sob o título de "Conexões sustentáveis São Paulo - Amazônia: quem se beneficia com a destruição da Amazônia” - foi este o estudo que identificou a necessidade de criar o programa; Documento do Greenpeace (2009), "A farra do boi na Amazônia", em que foram investigados os frigoríficos que mantêm ligação com o crescimento da pecuária na Amazônia causando desmatamento para abastecer o mundo com carne.

3) Entrevista: são conversas guiadas, provavelmente fluidas, não rígidas. A 
entrevista em profundidade é um tipo de entrevista em que o pesquisador pergunta aos respondentes-chave sobre os fatos de um assunto (YIN, 2010). Foi entrevistada a pessoa responsável pelo programa com um roteiro semiestruturado com seis perguntas sobre as diretrizes do programa e do pacto, sobre o papel dos signatários e sobre a efetividade das ações; o intuito da entrevista foi aprofundar as informações colhidas nos documentos e registros.

Sobre a análise em estudos de caso, Eisenhardt (1989) afirma que é comum a elaboração de relatórios detalhados do estudo de caso que, frequentemente, são puras descrições, mas que são fundamentais para o desenvolvimento da ideia. Foi utilizada a análise de conteúdo que, para Bardin (2009), é um conjunto de técnicas de análise das comunicações que utiliza procedimentos sistematizados e objetivos de descrição do conteúdo das mensagens. Minayo (2001) expõe que a análise de conteúdo é uma forma de análise de informações sobre o comportamento humano.

\section{ANÁLISE DOS RESULTADOS}

Os resultados estão organizados em três tópicos atendendo aos objetivos específicos apresentados na introdução.

\subsection{CONTEXTUALIZAÇÃO DA PRODUÇÃO PECUÁRIA NA AMAZÔNIA}

A Amazônia brasileira, um dos maiores ecossistemas do mundo, sempre esteve no foco da mídia, das empresas e dos ambientalistas, e apresenta, em área, a maior média anual mundial de desmatamento, o setor da pecuária é apontado como o principal vetor. A pecuária é responsável por cerca de $80 \%$ do desmatamento na região. As ONGs ambientalistas afirmam que a floresta amazônica está sendo convertida em pasto. O setor pecuário na Amazônia brasileira é responsável por 14\% do desmatamento global anual (GREENPEACE, 2009).

Em 2008 foi identificado que a Amazônia contribuía diretamente para o aumento das exportações abastecendo os mercados das regiões Sul e Sudeste, que agrega valor e exporta parte de sua produção para outros países (SMERALDI; MAY, 2008). De acordo com a ONG Repórter Brasil e Papel Social Comunicação (2008) 
a Amazônia fornece matérias-primas, energia e outros produtos essenciais para a sobrevivência de muitas cidades, especialmente para o maior município do Brasil, São Paulo.

A pecuária cresceu na região amazônica em decorrência de alguns fatores, tais como o baixo custo da terra; expansão da produção de grãos ou cana-de-açúcar, que empurram a pecuária para a fronteira; geração de tecnologias de intensificação e manejo que permitem a consolidação de grandes atividades pecuárias (SMERALDI; MAY, 2008). O Greenpeace (2009) destaca a participação de três frigoríficos que abastecem mercados mundiais com carne e couros: Bertin, JBS-Friboi e Marfrig; e para reforçar a participação destes frigoríficos no mercado global, o governo brasileiro disponibilizou recursos para expandir a infraestrutura de processamento de produtos pecuários na Amazônia (ONG REPÓRTER BRASIL E PAPEL SOCIAL COMUNICAÇÃO, 2008).

O Greenpeace (2009) faz aconselhamentos direcionados a três grupos que compõem a cadeia de suprimentos da bovinocultura de corte. As indústrias frigoríficas e consumidoras devem parar de negociar com fazendas ou empresas envolvidas no desmatamento, apoiando uma moratória imediata no desmatamento, para impulsionar a inclusão de critérios ambientais no atual sistema de rastreabilidade da cadeia produtiva e influenciarem governos a criarem um fundo internacional de proteção das florestas tropicais. Por sua vez, o governo brasileiro deveria fortalecer a presença do estado na Amazônia, interromper as autorizações para novos desmatamentos, cortar financiamentos para empresas envolvidas com o desmatamento, implementar políticas públicas para zerar o desmatamento na Amazônia, implementar um sistema de rastreabilidade de toda a cadeia produtiva da pecuária, incluindo critérios ambientais. E, por fim, cabe aos governos dos países desenvolvidos apoiarem a criação de um mecanismo global de financiamento de proteção às florestas.

\subsection{DESCRIÇÃO DO PROGRAMA “CONEXÕES SUSTENTÁVEIS” - PACTO DA PECUÁRIA}

O Movimento Nossa São Paulo e o Fórum Amazônia Sustentável organizaram o programa "Conexões Sustentáveis" (2012a) que alerta sobre a responsabilidade 
das empresas, do governo e da sociedade em termos ambientais, para a preservação da floresta, e sociais, para o desenvolvimento das comunidades locais. Assim, o programa "Conexões Sustentáveis" considera as relações que há entre a Amazônia e São Paulo. São nove estados brasileiros que fazem parte da Amazônia Legal: Acre, Amazonas, Amapá, parte do Maranhão, Mato Grosso, Pará, Rondônia, Roraima e Tocantins. O estado de São Paulo, o estado brasileiro mais populoso, que abriga a cidade de São Paulo, capital, a maior cidade do Brasil em termos populacionais, com 11.253.503 habitantes em 2010 (IBGE, 2011).

Os documentos do programa "Conexões Sustentáveis" determinam para os signatários que o financiamento, a distribuição e a comercialização de produtos com certificação (ou que estejam em processo de regularização) devem ser provenientes de fornecedores que não façam parte da Lista Suja do Trabalho Escravo ou de áreas embargadas pelo IBAMA (Instituto Brasileiro do Meio Ambiente e dos Recursos Naturais Renováveis) (CONEXÕES SUSTENTÁVEIS, 2012a). Em suma, com base na entrevista e nos documentos analisados, os signatários do pacto da pecuária não devem estabelecer negócios com empresas e pecuaristas que estejam listados junto ao MTE (Ministério do Trabalho e Emprego) em relação ao trabalho escravo, e também daqueles fornecedores que estejam localizados nas áreas embargadas pelo IBAMA (CONEXÕES SUSTENTÁVEIS, 2012b; 2012f). Para validar as ações declaradas pelos signatários como suficientes para o cumprimento do pacto existe um Comitê de Acompanhamento, este comitê avalia se as informações fornecidas são suficientes para o cumprimento dos compromissos e se de fato foram colocadas em prática (CONEXÕES SUSTENTÁVEIS, 2012d).

A Prefeitura de São Paulo também assinou um termo de compromisso para que as compras públicas ajudem a preservar a Amazônia (MOVIMENTO NOSSA SÃO PAULO, 2010). No sentido de garantir alguns destes itens, há uma Lei Municipal, de $\mathrm{n}^{\mathrm{o}} 15.120$, de 14 de janeiro de 2010, que estabelece os procedimentos de controle ambiental e social para a compra de carne bovina no município de São Paulo (SÃO PAULO, 2010). Segundo a Lei, nas aquisições de carne bovina "in natura", os licitantes devem declarar que a carne a ser fornecida não é oriunda de gado criado em áreas que tenham ocorrido desmatamento irregular, nem de terras indígenas invadidas, $\mathrm{e}$ que não contem em toda sua cadeia produtiva a utilização de trabalho infantil ou escravo. 
O frigorífico, no processo de compras públicas municipais de carne bovina, deve apresentar o histórico de procedência da carne, acompanhado de um ou mais dos documentos: Guia de Trânsito Animal (GTA), mostrando o deslocamento do gado bovino entre a propriedade rural e o frigorífico; nota ou documento fiscal comprovando a origem do gado usado no abate; relatório de rastreabilidade bovina de entidade idônea e/ou certidão negativa de débito com o IBAMA (CONEXÕES SUSTENTÁVEIS, 2012c).

\section{3 “CONEXÕES SUSTENTÁVEIS" E A CADEIA DE SUPRIMENTOS VERDE}

O programa "Conexões Sustentáveis" é um esforço para que os agentes da cadeia se suprimentos, signatários do pacto da pecuária, se organizem em prol de uma ação socioambiental. Os ideais do programa são apresentados no Quadro 2:

Quadro 2. Requisitos para os signatários do pacto da pecuária do programa "Conexões Sustentáveis"

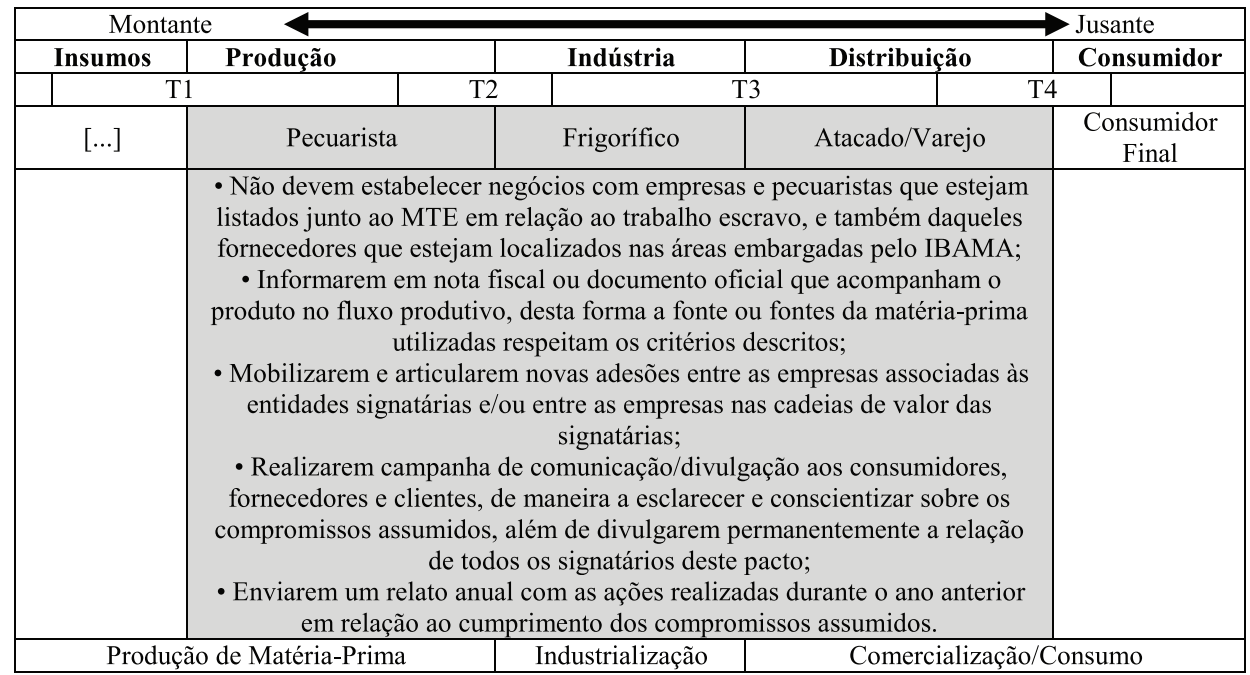

Fonte: Elaborado pelos autores.

Entretanto, em fevereiro de 2011, o programa "Conexões Sustentáveis" apresentou fatos relevantes do pacto da pecuária, no qual se destacam a participação dos signatários do pacto. Estes fatos expõem problemas quanto aos requisitos do pacto, são verificados neste tópico quanto às regras do programa e confrontados 
com a teoria de cadeia de suprimentos verde. Evidenciam-se nestes fatos os três principais agentes econômicos da cadeia de suprimentos: produtor/pecuarista, indústria frigorífica e o varejo (BECHTEL; JAYARAM, 1997; ARAÚJO, 2006). O não cumprimento dos requisitos do programa "Conexões Sustentáveis" é apresentado no Quadro 3, a seguir:

Quadro 3. Não cumprimento dos requisitos do programa "Conexões Sustentáveis"

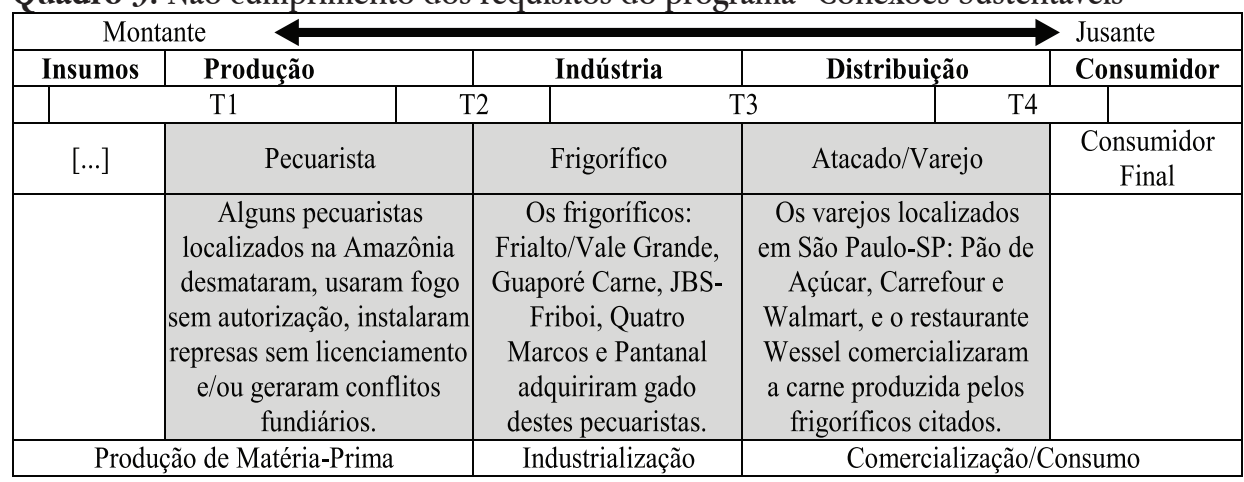

Fonte: Elaborado pelos autores.

O Quadro 3 expõe o não cumprimento dos requisitos do programa "Conexões Sustentáveis", assim são apresentadas as situações de alguns pecuaristas que promoveram impactos socioambientais negativos (desmatamento, uso de fogo sem autorização, instalação de represas sem autorização e conflitos fundiários); diante destas situações, tais pecuaristas não deveriam ser fornecedores de gado para os frigoríficos signatários. Isto exige que os frigoríficos realizem uma avaliação e seleção de seus fornecedores, o mesmo deve ocorrer com os varejos, que devem avaliar os frigoríficos e exigirem destes o cumprimento das normas. Desta forma os agentes pecuaristas, frigoríficos e varejo são corresponsáveis pelos atos ao longo da cadeia de suprimentos.

Para o programa "Conexões Sustentáveis" (2012b) todas as empresas signatárias devem acompanhar o produto no fluxo produtivo, verificando se a fonte da matéria-prima respeita os critérios do programa, corroboram Rao e Holt (2005) e Srivastava (2007) que afirmam que a cadeia de suprimentos verde incorpora ações intra e interorganizacionais envolvendo aspectos socioambientais. Em outras palavras a cadeia de suprimentos verde representa um conjunto recente 
e importante de práticas de gestão socioambiental intra e interorganizacional, que deve ser incorporada em todos os agentes econômicos da cadeia e em cada etapa da gestão (ZHU et al., 2008).

\section{CONCLUSÕES}

Este artigo se propôs analisar a contribuição do pacto da pecuária do programa chamado "Conexões Sustentáveis" São Paulo - Amazônia para o desenvolvimento da cadeia de suprimentos verde da bovinocultura de corte. A cadeia de suprimentos verde é um termo amplo que abarca ações intra e interorganizacionais em termos socioambientais, em que todos os agentes econômicos são tidos como corresponsáveis por um bom desempenho social e ambiental. O pacto da pecuária do programa "Conexões Sustentáveis" integra todos os agentes, tanto a montante quanto a jusante, cabendo aos signatários a verificação das questões socioambientais ao longo de toda a cadeia de suprimentos. Isto ainda não está claro para os signatários, pois alguns entendem que o compromisso de adquirirem produtos dentro das regras estabelecidas envolve tão somente o fornecedor direto e não os demais agentes. Atrelado a isto o programa apresenta problemas para sua efetivação.

Os resultados da pesquisa mostraram que a comercialização de gado entre os pecuaristas localizados na Amazônia apresenta problemas ambientais e/ ou fundiários. Foi possível notar que algumas propriedades rurais desta região, produtoras de gado, são responsáveis por desmatamento ilegal, trabalho escravo e/ ou estão localizadas em áreas irregulares (terras indígenas, quilombolas e unidades de conservação). Existem frigoríficos que adquirem gado destas propriedades rurais ou destes pecuaristas - por vezes os produtores transportam o gado de uma fazenda embargada para outra regular, na tentativa dos frigoríficos relacionarem os problemas socioambientais à propriedade e não ao proprietário. Os frigoríficos, por sua vez, fornecem carne para redes de supermercados e restaurantes, que chega aos consumidores finais.

O programa "Conexões Sustentáveis" aponta que estas situações não atendem aos requisitos do pacto da pecuária. As situações listadas também não condizem com a teoria de cadeia de suprimentos verde. Entretanto, verifica-se que 
o pacto da pecuária do programa "Conexões Sustentáveis" busca contribuir para o desenvolvimento da cadeia de suprimentos verde da bovinocultura de corte. As atividades do programa envolvem o incentivo e o acompanhamento do desempenho socioambiental das empresas e das transações entre os agentes econômicos da cadeia de suprimentos da bovinocultura de corte considerando questões ambientais e sociais.

Considera-se como um limitador do estudo o fato que o programa "Conexões Sustentáveis" é recente, iniciou-se em 2009, portanto possui poucos dados sobre o resultado global do programa, os dados apresentados expuseram os problemas com os signatários, no entanto deve haver casos de sucesso que o programa não divulga. Para trabalhos futuros sugerem-se estudos empíricos que envolvam diretamente os signatários, para verificar barreiras e dificuldades desses agentes econômicos no atingimento de metas do programa "Conexões Sustentáveis" e para o desenvolvimento de cadeia de suprimentos verde.

\section{REFERÊNCIAS}

ARAÚJO, G. C. O processo de implantação da sustentabilidade em frigoríficos. 2006. 169f. Dissertação (Mestrado em Agronegócios) - Universidade Federal de Mato Grosso do Sul, Campo Grande-MS, 2006.

BÁNKUTI, F. I.; SOUZA FILHO, H. M. A informalidade em sistemas agroindustriais: os casos dos sistemas agroindustriais da carne bovina e do leite. IN: ZUIN, L. F. S.; QUEIROZ, T. R. Agronegócio: gestão e inovação. São Paulo: Saraiva, 2006.

BARDIN, L. Análise de conteúdo. Lisboa, Portugal: Edições 70, LDA, 2009.

BEAMON, B. M. Designing the green supply chain, Logistics information management, v. 12, n. 4, p. 332-342, 1999a.

BEAMON, B. M. Measuring supply chain performance, International journal of operations \& production management, v. 19, n. 3, p. 275-292, 1999 b.

BECHTEL, C.; JAYARAM, J. Supply chain management: a strategic perspective, The international journal of logistics management, v. 8, n. 1, p. 15-34, 1997. 
BORRÁS, M. A. A.; TOLEDO, J. C. de. A coordenação de cadeias agroindustriais: garantindo a qualidade e competitividade no agronegócio. IN: ZUIN, L. F. S.; QUEIROZ, T. R. (Org.) Agronegócios: gestão e inovação, Saraiva, São Paulo, 2006.

CHRISTOPHER, M. Logistics and supply chain management. London: Pit-man Publishing, 1992.

COLLIS, J.; HUSSEY, R. Pesquisa em administração. 2. ed. Porto Alegre: Bookman, 2005.

CONEXÕES SUSTENTÁVEIS. Termo de compromisso candidatos. Disponível em: $<$ http://www.conexoessustentaveis.org.br/conteudo.php?id=163 > . Acesso em: 10 maio 2012a.

CONEXÕES SuSTEntÁVEIS. Pacto da Pecuária. Disponível em: <http://www. conexoessustentaveis.org.br/conteudo.php?id=143 > . Acesso em: 10 maio 2012b.

CONEXÕES SUSTENTÁVEIS. Conexóes sustentáveis busca influenciar na regulamentação da Lei da Carne, aprovada em São Paulo. Disponível em: $<$ http://www.conexoessustentaveis.org.br/exibe.php?id=1390>. Acesso em: 10 maio 2012c.

CONEXÕES SUSTENTÁVEIS. Acompanhamento dos pactos. Disponível em: $<$ http://www.conexoessustentaveis.org.br/conteudo.php?id=128>. Acesso em: 10 nov. 2012d.

CONEXÕES SUSTENTÁVEIS. Pactos setoriais. Disponível em: <http:// conexoessustentaveis.org.br/estudo2011/?page_id=8 > . Acesso em: 20 out. 2012e.

CONEXÕES SUSTENTÁVEIS. Pacto: pecuária. Disponível em: < http://www.ethos. org.br/sistemas/ConexoesSustentaveisNovo/pecuaria/istaSignatarios.asp >. Acesso em: 20 out. 2012f.

CONEXÕES SUSTENTÁVEIS. Pecuária: o que está por trás do churrasco? Disponível em: < http://conexoessustentaveis.org.br/estudo2011/?p=80>. Acesso em: 23 out. 2012g. 
CONEXÕES SUSTENTÁVEIS. Carne: crimes ambientais, conflitos fundiários. Disponível em: < http://conexoessustentaveis.org.br/estudo2011/?p=141> . Acesso em: 23 out. $2012 \mathrm{~h}$.

CONEXÕES SUSTENTÁVEIS. Um pecuarista multado em $\mathbf{R} \$ 14$ milhões. Disponível em: < http://conexoessustentaveis.org.br/estudo2011/?p=145> . Acesso em: 23 out. 2012i.

CONEXÕES SUSTENTÁVEIS. Caso: carne - crimes ambientais, conflitos fundiários (íntegra do posicionamento das empresas). Disponível em: < http:// conexoessustentaveis.org.br/estudo2011/wp-content/uploads/2011/02/RespostaCase-101.pdf > . Acesso em: 27 out. 2012j.

CONEXÕES SUSTENTÁVEIS. Caso: um pecuarista multado em $\mathrm{R} \$ 14$ milhões (íntegra do posicionamento das empresas). Disponível em: < http://conexoessustentaveis. org.br/estudo2011/wp-content/uploads/2011/02/Resposta-Case-91.pdf>. Acesso em: 27 out. 2012k.

COOPER, D. R.; SCHINDLER, P. S. Métodos de pesquisa em administração. 7. ed. Porto Alegre: Bookman, 2003.

DARNALL, N.; JOLLEY, G. J.; HANDFIELD, R. Environmental management systems and green supply chain management: complements for sustainability? Business strategy and environment, v. 17, p. 30-45, 2008.

DIAS-FILHO, M. B. Degradação de pastagens: processos, causas e estratégias de recuperação. 3. ed. Belém: Embrapa Amazônia Oriental, 2007.

EISENHARDT, K. M. Building theories from case study research, Academy of management review, v. 14, n. 4, p. 532-550, 1989.

GODOY, A. S. Pesquisa qualitativa: tipos fundamentais, Revista de administração de empresas, São Paulo, v. 35, n. 3, p. 20-29, 1995.

GREENPEACE. A farra do boi na Amazônia, junho 2009. Disponível em: < http:// www.greenpeace.org/brasil/Global/brasil/report/2009/6/FARRAweb-alterada.pdf $>$. Acesso em: 15 nov. 2011. 
HAIR JR., J. F. et al. Fundamentos de métodos de pesquisa em administração. Porto Alegre: Bookman, 2005.

IBGE Cidades@. São Paulo. Disponível em: < http://www.ibge.gov.br/cidadesat/ link.php?codmun=355030> . Acesso em: 27 nov. 2011.

LAMBERT, D. M.; COOPER, M. C. Issues in supply chain management. Industrial marketing management, New York, v. 29, p. 65-83, 2000.

LAZZARINI, S. G.; CHADDAD, F. R.; COOK, M. L. Integrating supply chain and network analysis: the study of netchains, Journal on chain and network science, Wageningen, n.1, p. 7-22, 2001.

MAPA, Ministério da Agricultura, Pecuária e Abastecimento. Pecuária. Disponível em: <http://www.agricultura.com.br > . Acesso em: 20 set. 2011.

MAY, T. Pesquisa social: questões, métodos e processos. 3. ed. Porto Alegre: Artmed, 2004.

MENTZER, J. T. et al. Defining supply chain management, Journal of business logistics, v. 22, n. 2, p. 1-25, 2001. Disponível em: < http://engsci.aau.dk/kurser/ F06/Lscm/Lscm/Lesson\%201/DEFINING\%20SUPPLYCHAIN\%20MANAGEMENT. pdf > . Acesso em: 13 nov. 2011.

MICHELS, I. L.; SPROESSER, R. L.; MENDONÇA, C. G. Cadeia produtiva da carne bovina de Mato Grosso do Sul. Campo Grande, MS: Oeste, 2001.

MIN, H.; GALLE, W. P. Green purchasing practices of US firms. International journal of operations \& production management, v. 21, n. 9-10, p. 1222-1238, 2001.

MINAYO, M. C. S. (Org.). Pesquisa social: teoria, método e criatividade. Rio de Janeiro: Vozes, 2001.

MOVIMENTO NOSSA SÃO PAULO. Plataforma Cidades Sustentáveis, Julho 2010. Disponível em: $<$ http://www.cidadessustentaveis.org.br/downloads/publicacaoweb. pdf $>$. Acesso em: 08 maio 2011.

ONG REPÓRTER BRASIL E PAPEL SOCIAL COMUNICAÇÃO. Conexões sustentáveis 
São Paulo - Amazônia: quem se beneficia com a destruição da Amazônia, 2008. Disponível em: <http://www.reporterbrasil.org.br/documentos/conexoes sustentaveis.pdf $>$. Acesso em: 15 nov. 2011.

PIGATTO, G.; ALCÂNTARA, R. L. C. Relacionamento colaborativo nos canais de distribuição. IN: ZUIN, L. F. S.; QUEIROZ, T. R. (Org.) Agronegócios: gestão e inovação, São Paulo: Saraiva, 2006.

RAO, P.; HOLT, D. Do green supply chains lead to competitiveness and economic performance? International journal of operations \& production management, v. 25, n. 9, p. 898-916, 2005.

RICHARDSON, R. J. Pesquisa social: métodos e técnicas. 3. ed. Altas: São Paulo, 2008.

SÃO PAULO. Lei $\mathrm{n}^{\mathrm{O}}$ 15.120, de 14 de janeiro de 2010. Estabelece procedimentos de controle ambiental para a aquisição de carne bovina "in natura" pelo Município de São Paulo, e dá outras providências. Diário Oficial da Cidade de São Paulo, São Paulo, v. 55, n. 9, p. 3, 15, jan. 2010.

SARKIS, J. A strategic decision framework for green supply chain management. Journal of cleaner production, v. 11, n. 4, p. 397-409, jun. 2003.

SEVERO, C. M.; MIGUEL, L. A. A sustentabilidade dos sistemas de produção de bovinocultura de corte do estado do Rio Grande do Sul. Redes, Universidade de Santa Cruz do Sul (UNISC), v. 11, n. 3, p. 213-234, set./dez. 2006.

SMERALDI, R.; MAY, P. H. O reino do gado: uma nova fase na pecuarização da Amazônia. São Paulo: Amigos da Terra, 2008.

SRIVASTAVA, S. K. Green supply-chain management: a state-of-the-art literature review, International journal of management reviews, v. 9, p. 53-80, 2007.

USDA. United States Departament of Agriculture. Livestock and poultry: world markets and trade, April, 2011. Disponível em: < http://www.fas.usda.gov/dlp/ circular/2011/livestock_poultry.pdf > . Acesso em: 28 set. 2011.

WALKER, H.; SISTO, L.; MCBAIN, D. Drivers and barriers to environmental supply chain management practices: lessons from the public and private sectors, Journal of 
purchasing \& supply chain management, v. 14, p. 69-81, 2008.

YIN, R. Estudo de caso: planejamento e métodos. 4. ed. Porto Alegre: Bookman, 2010.

ZHU, Q.; SARKIS, J. An inter-sectoral comparison of green supply chain management in China: drivers and practices. Journal of cleaner production, v. 14, n. 5, p. 472486, 2006.

ZHU, Q.; SARKIS, J. Relationships between operational practices and performance among early adopters of green supply chain management practices in Chinese manufacturing enterprises, Journal of operations management, v. 22, n. 3, p. 265289, 2004.

ZHU, Q.; SARKIS, J.; LAI, K. Green supply chain management: pressures, practices and performance within the Chinese automobile industry. Journal of cleaner production, v. 15, n. 11-12, p. 1041-1052, 2007.

ZHU, Q.; SARKIS, J.; LAI, K. Green supply chain management implications for "closing the loop". Transportation research part E: logistics and transportation Review, v. 44, n. 1, p. 1-18, jan, 2008.

ZSIDISIN, G. A.; SIFERD, S. P. Environmental purchasing - a framework for theory development. European journal of purchasing \& supply management, v. 7, p. 61-73, 2001.

Recebido em: 01 de março de 2014

Aceito em: 28 de setembro de 2014 